\title{
The Level of Awareness on Electrical Hazards and Safety Measures among Residential Electricity User's in Minna Metropolis of Niger State, Nigeria
}

\author{
${ }^{1}$ Saba, T. M., ${ }^{2}$ Tsado, J. PhD, ${ }^{1}$ Raymond, E. PhD ${ }^{3}$ Adamu, M. J. \\ ${ }^{1}$ Industrial and Technology Education Department. Federal University of Technology Minna,Niger State \\ ${ }^{2}$ Electrical and Electronic Engineering Department Federal University of Technology, Minna, Niger State. \\ ${ }^{3}$ Electrical and Electronics Technology Education Department College of Education Minna, Niger State.
}

\begin{abstract}
Electrical hazards and safety measure awareness of residential electricity user's plays significant role in enhancing safety of lives and property. Consequently the study assessed the level of electrical hazards and safety measures awareness among electricity users in Minna metropolis. Two research questions and two hypotheses were formulated and tested at 0.05 level of significant. Questionnaire was the sole instrument used for the study, distributed to 250 male and 210 female respondents in Minna metropolis using purposively sampling techniques. Mean, standard deviation and Z-test was use to analyze research questions and hypotheses. The findings that emerged among others are; electricity users are aware of improper electrical installation and damage electrical appliance and equipment as hazards and they were not aware of ungrounded circuit and equipment and coiled extension leads as hazards. On the safety measures, they are knowledgeable on proper electrical insulation and switching off and unplug equipment to be repaired. And not knowledgeable about uncoiled extension cord on the drum and when circuit breaks or fuses trip should not be reset till fault is detected. The following recommendations were made among others are; they should be public awareness on electrical hazards and safety by government and NGOs on Hazards and safety practices attributed to each equipment, appliances and machines should be conspicuously printed on it.
\end{abstract}

Key words: level of Awareness, Electrical Hazards and Safety, Residential Electricity User's

\section{Introduction}

Electricity is used in many ways such as lighting, cooling, heating and it is use to power or drive electrical equipment and machines. Electricity helps to facilitate economic development and it is a well known fact that electricity is essential to everyday life, without it life will be boring both at home and at the work place. Electricity passes more easily through some materials than others. Some substances such as metals generally offer very low resistance to the flow of electric current and such materials are called "conductors." Another conductor which is usually overlooked is the surface or subsurface of the earth. While insulator materials offer high resistance to the flow of electric current among the examples are rubber, dry wood, plastic and clothing (Bakshi, and Bakshi, 2009). Electricity normally travels in closed circuits, through a conductor, but sometimes a person's body which is an efficient conductor of electricity mistakenly becomes part of the electric circuit. This can lead to an electrical shock. Electric shocks occur when a person's body completes the current path having both wires of an electric circuit, one wire of an energized circuit, the ground and a metal part that accidentally becomes energized due to a break in its insulation or another "conductor" that is carrying a current (Floyd, Rogers, and Uzoka, 2008).

Circuit protection is very important in any electrical installation as it prevent fire hazards. Circuit protection limit or stop the passage of current automatically in the event of an overload, ground fault, or short circuit in the wiring system. Grounding in an electrical system means intentionally providing a low-resistance path that connects to the earth. This prevents the accumulation of voltages that could cause an electrical accident in an installation. Grounding is normally a secondary protective measure to protect against electric shock and it does not completely guarantee the person from a shock or be injured or killed by an electrical current (Seip, 2000).

Despite the important of electricity in day to day life, Electricity is often referred to as a "silent killer" because it cannot be tasted, seen, heard, or smelled. It is essentially invisible. It is a destroyer of properties if not handle with respect. Electricity is invisible in nature and it is long recognized as a serious hazard at residential, commercial areas, institutions of learning and other places. Cadick, Capelli-Schellpferffer and Neitzel ( 2006) said that in the late $1800 \mathrm{~s}$, hotels had to place signs assuring their guests that electricity is harmless, but by late 1900 s, signs had to be hung to remind people that electricity is a hazard. MacKinnon, (2010) said that the presence of electricity is increasing in modern live and we ought to know that more electricity usage means more potential electrical hazards. As people continue to put confidence on electricity, so does the importance of 
electrical safety awareness for the electricity users becomes necessary. People can never be too young to start learning to use electricity safely. He makes an estimation that 53,000 electrical fires occur in homes each year. Most of these can be avoided by taking simple safety precautions. Electricity is a powerful and versatile energy but can be dangerous if it is not used properly. Most of the accidents that occur are due either to carelessness or to a lack of awareness of some basic rules that should be observed when using electricity (Networks, n.d). The use of electricity is something taken for granted, but using it safely is very important. By understanding how electricity works and where it is found, we can each do our part in preventing electrical dangers no matter where we are (MacKinnon, 2010). Hazard can be defined as any potential or actual threat to the well being of people, equipment, machinery or environment. Hazard can also be seen as something that can be identified as measured of potential source of danger such as naked electricity wires, electricity gadgets which are not switched off, unsafe acts, unprotected installation, over load socket outlet and many others (Cadick, Capelli-Schellpferffer and Neitzel 2006).

The electric shock may likely occur when the body becomes part of an electric circuit and there are three ways or path that may lead to electric shocks such as: A person may have contact with both conductors in a circuit; A person may provide a way between an ungrounded conductor and the ground.; A person may provide a way between the ground and a conducting material that is in contact with an ungrounded conductor. Taylor, Easter and Hegney (2004) observed that, the degree of shock an individual may receive is dependent on several factors, including skin resistance. Skin resistance is greatly reduced when the skin is wet or moist, and so the degree of shock will be greater. Other factors include the: The amount of current that is conducted through the body; the path of the current through the body; the duration of time a person is subjected to the current and status of the individual.

The effect of electric shocks ranges from stop of the heart or the breathing muscles, or both, burns, bleeding, neurological damage and ventricular fibrillation. Electricity always follows the shortest circuit path of least resistance. If a human body creates a path to follow, electricity will flow to the ground or complete a circuit through the body. According to Cadick, Capelli-Schellpferffer and Neitzel ( 2006) the effects of electric shocks are severe and the table below presents the amount of current and its effect on human body.

\begin{tabular}{|l|l|}
\hline Current in milliamperes & Effects \\
\hline 1 or less & No sensation, probably no effect noticed \\
1 to 3 & Mild sensation not painful \\
3 to 10 & Painful shock \\
10 to 30 & Muscular control could be lost or muscle clamping \\
30 to 75 & Respiratory paralysis \\
$75 \mathrm{~mA}$ to 4 amps & Ventricular fibrillation \\
Over 4 amps & Tissue begins to burns. Heart muscles clamp and heart stops beating. \\
\hline
\end{tabular}

Source: Cadick, Capelli-Schellpferffer and Neitzel ( 2006)

Electricity plays important role to mankind and national development, it is usually referred to as bad master when used wrongly. Electricity is no respecter of persons; it will injure or kill a custodian, manager, rich, poor, president, or office worker just as fast as it will injure or kill an electrician. The is no record of electric hazards causality by gender that is to say if male do become victim of electrical hazards such shock, electrocution and other hazards than there female counterpart in their household? It is also not certain who among the male and female are more educated on electrical hazards and safety but observations shows many female do not want to touch electrical equipment and appliances. Although electrical accident has been causing serious looses such as economic and social, for instance injuries, losses of lives and valuable properties among electrical energy users. It is quite unfortunate that this electricity which is essential to lives constitute a major hazard to man and property. Whenever you work with power tools or on electrical circuits there is a risk, especially electric shock. Anyone can be exposed to these hazards at home or at work. Electricity can be dangerous and should be approached with caution; any forms of energy, when not properly controlled or harnessed can result in serious danger to those who use it (Kolak, 2007).

In view of the relevance of electricity to man, effort should be made to educate everyone on the use of electricity to meet human needs because electrical hazard pose a significant risk of death and injuries to individuals. Therefore, attention to safety is the necessary first step in any environmental set up. More than onethird of electrical fatalities, death and injuries, losses of valuable properties are due to electricity (OSHA, 2009).

According to Jarnick (2008) fires that occur in the home, market, offices and other places as a result of electricity are initiated as a result of improper and careless use of electrical equipment and improper protection of installation. Due to the danger electricity poses to the existence of biological lives, efforts are made to assess the level of electrical hazards and safety measures awareness among electricity users. 


\section{Purpose of the Study}

The main purpose of this study is to assess the level of electrical hazards and safety measures awareness among electricity users in Minna Metropolis; specifically the study will determine:

1. The level of electrical hazards awareness among electricity users in Minna metropolis.

2. The level of safety measures awareness among electricity users in Minna metropolis.

\section{Research Questions}

In order to achieve the objective of the study, the following research questions were formulated to guide the study:

1. What is the level of electrical hazards awareness among electricity users in Minna metropolis?

2. What is the level of safety measures awareness among electricity users in Minna metropolis?

\section{Hypotheses}

The following null hypotheses was stated and tested at $\mathrm{P}<0.05$ level of significance in order to guide the study: $\mathbf{H o}_{1}$ : There is no statistical significant difference between the mean responses of Male electricity users and Female electricity users with respect to their perceptions on level of electrical hazards awareness among electricity users in Minna metropolis.

$\mathbf{H o}_{2}$ : There is no statistical significant difference between the mean responses of Male electricity users and Female electricity users with respect to their perceptions on level of safety measures awareness among electricity users in Minna metropolis.

\section{Methodology}

The research design used in carrying out this study was a survey method. Survey research is one in which a group of people or items is studied by collecting and analyzing data from only a few people or items considered to be representative of the entire group to determine the level of electrical hazards and safety measures awareness among electricity user's in Minna metropolis. This study covers Minna metropolis a capital town of Niger State, Nigeria. The study utilized electricity user's as the population. Purposive sampling was adopted as the populations of the electricity users were not known. 250 male electricity users and 210 female electricity users were used in Dutse-Kura, Bosso, Tunga and Chanchaga within Minna town.

The questionnaire was the sole instrument developed by the researcher for the collection of data and was validated by Lecturers in Electrical and Electronics Engineering and Industrial and Technology Education Department, Federal University of Technology Minna. The analysis of data for the research questions and hypotheses were accomplished using frequency counts, mean, standard deviation and Z - test at .05 level of significant. The mean value of 2.50 was used as a decision point at four point rating scale and any item that has it mean rating of 2.50 and above was considered aware or knowledgeable and any item that has the mean item below 2.50 was considered not aware and not knowledgeable. For hypotheses testing the Z- critical value of 1.98 was used at 458 degree of freedom. Any hypothesis having $\mathrm{Z}$ - calculated of 1.98 and below was considered accepted and above 1.98 was considered rejected.

\section{Research Question 1.}

What is the level of electrical hazards awareness among electricity users in Minna metropolis?

Table 1: Mean Responses of Male electricity users and Female electricity users on the level of electrical hazards awareness among electricity users in Minna metropolis.

$$
\mathrm{N}_{1}=250, \mathrm{~N}_{2}=210
$$

\begin{tabular}{|c|c|c|c|c|c|}
\hline $\mathbf{S} / \mathbf{N}$ & ITEM & $\overline{X_{1}}$ & $\overline{X_{2}}$ & $\overline{X_{t}}$ & Remarks \\
\hline 1 & Inadequate electrical protection of installation & 3.03 & 3.11 & 3.22 & Aware \\
\hline 2 & Improper insulation & 2.80 & 2.49 & 2.65 & Aware \\
\hline 3 & Ungrounded circuit and equipment & 2.23 & 2.00 & 2.19 & Not Aware \\
\hline 4 & Damage electrical appliance and equipment & 2.56 & 2.65 & 2.74 & Aware \\
\hline 5 & Coiled extension leads & 2.05 & 1.69 & 2.06 & Not Aware \\
\hline 6 & Covered ventilation holes in electrical equipment & 2.55 & 2.32 & 2.43 & Not Aware \\
\hline 7 & Pulling the plug out of a socket outlet by the cable & 2.45 & 2.28 & 2.40 & Not Aware \\
\hline 8 & Fixing of wall socket or switches in the bathroom & 2.41 & 1.98 & 2.14 & Not Aware \\
\hline 9 & Lighting fitting overheating & 3.43 & 3.01 & 3.10 & Aware \\
\hline 10 & High voltage bulb on lower lighting fitting & 2.00 & 2.05 & 1.90 & Not Aware \\
\hline 11 & Intentional use of obviously defective and unsafe tools & 3.23 & 3.42 & 3.40 & Aware \\
\hline 12 & Failure to de energize electrical equipment when it is being repaired or inspected & 2.87 & 2.60 & 2.74 & Aware \\
\hline 13 & Loose connections & 2.90 & 2.87 & 2.96 & Aware \\
\hline 14 & Use of tools or equipment too close to energized parts & 2.04 & 2.16 & 1.96 & Not Aware \\
\hline 15 & Defective parts & 2.78 & 2.42 & 2.58 & Aware \\
\hline 16 & Ground faults in equipment & 2.43 & 2.45 & 2.34 & Not Aware \\
\hline
\end{tabular}


The Level of Awareness on Electrical Hazards and Safety Measures among Residential ....

\begin{tabular}{clrrrr}
\hline 17 & Over load of socket outlet & 2.43 & 2.21 & 2.02 & Not Aware \\
18 & Placing socket outlet in wet ground & 2.57 & 2.09 & 2.21 & Not Aware \\
\hline Key & & & & &
\end{tabular}

$\mathrm{N}_{1}=$ Male Electricity Users, $\mathrm{N}_{2}=$ Female Electricity Users, $\bar{X}_{1}=$ Mean of responses of Male Electricity Users, $\bar{X}_{2}=$ Mean of responses of Female Electricity Users, $\bar{X}_{\mathrm{t}}=$ Average mean of responses of Male and Female Electricity Users.

Table1. Show the level of electrical hazards awareness among electricity users in Minna metropolis. This indicated that people are aware of certain electrical hazards and also they are still ignorant of some hazards despite long time of electricity usage. The results indicated that male were more aware of hazards while using electricity compare to female.

\section{Research Question 2.}

What is the level of safety measures awareness among electricity users in Minna metropolis?

Table 2: Mean Responses of Male electricity users and Female electricity users on the level of electrical safety measures awareness among electricity users in Minna metropolis.

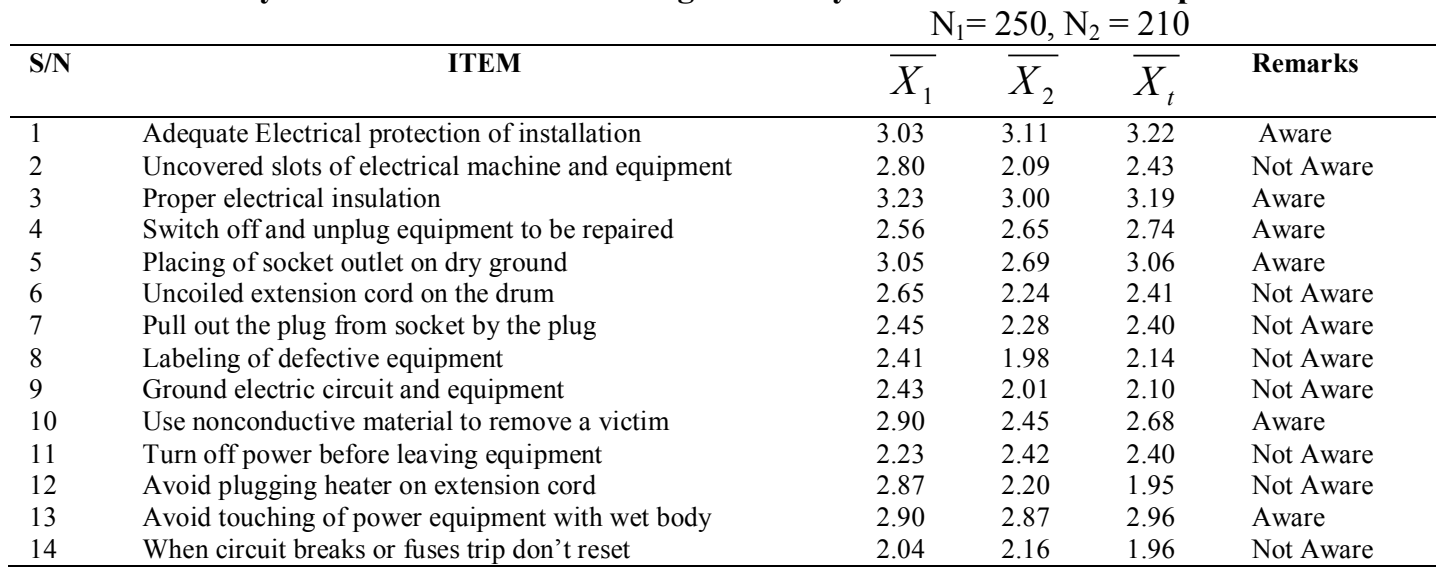

Table 2 revealed the level of safety measures knowledge among electricity users in Minna metropolis, shows that many people have no Knowledge of safety measures when using electricity. The results indicated that male were more knowledgeable in safety measures compare to female.

\section{Hypothesis One}

There is no statistical significant difference between the mean responses of Male electricity users and Female electricity users with respect to their perceptions on level of electrical hazards awareness among electricity users in Minna metropolis.

Table 4: Z-test Analysis of Male and Female electricity users with respect to their perceptions on level of electrical hazards awareness among electricity users in Minna metropolis.

\begin{tabular}{lcccccccc} 
& & \multicolumn{5}{c}{$\mathbf{N}_{\mathbf{1}}=\mathbf{2 5 0}, \mathbf{N}_{\mathbf{2}}=\mathbf{2 1 0}$, t-critical = 1.96 } \\
\hline \multicolumn{1}{c}{ Respondents } & $\mathbf{N}$ & Mean & S.D & df & $\mathbf{P}$ & z-cal & z-critical & Decision \\
\hline Male & 250 & 2.75 & 0.16 & \multirow{2}{*}{458} & .05 & 3.62 & \multirow{2}{*}{1.96} & \multirow{2}{*}{ S $^{*}$} \\
Female & 210 & 2.37 & 0.22 & &
\end{tabular}

* Significant, N; Number of Respondents, S.D: Standard Deviation, d.f; Degree of Freedom, P: Probability of

Testing

The result of z-test presented in Table 3 shows that $\mathrm{z}$-cal was 3.62. This implies that there is significant difference $(\mathrm{P}>.05)$ in the mean responses of Male electricity users and Female electricity users with respect to their perceptions on level of electrical hazards awareness among electricity users in Minna metropolis.

\section{Hypothesis Two}

There is no statistical significant difference between the mean responses of Male electricity users and Female electricity users with respect to their perceptions on level of safety measures awareness among electricity users in Minna metropolis. 
The Level of Awareness on Electrical Hazards and Safety Measures among Residential ....

\begin{tabular}{|c|c|c|c|c|c|c|c|c|}
\hline Respondents & $\mathbf{N}$ & Mean & S.D & df & $\mathbf{P}$ & z-cal & z-crit & Decision \\
\hline $\begin{array}{l}\text { Male } \\
\text { Female } \\
\end{array}$ & $\begin{array}{l}250 \\
210 \\
\end{array}$ & $\begin{array}{l}2.75 \\
2.37 \\
\end{array}$ & $\begin{array}{l}0.16 \\
0.22 \\
\end{array}$ & 258 & .05 & 3.62 & 1.96 & $\mathrm{~S}^{*}$ \\
\hline
\end{tabular}

* Significant; $\mathrm{N}=$ Number of Respondents; S.D $=$ Standard Deviation; d.f $=$ Degree of Freedom; $\mathrm{P}=$ Probability of Testing

The result of z-test presented in Table shows that z-cal was 3.62. This implies that there is significant difference $(\mathrm{P}>.05)$ in the mean responses of Male electricity users and Female electricity users with respect to their perceptions on level of safety measures awareness among electricity users in Minna metropolis.

\section{Findings}

The electricity users are aware of the followings as electrical Hazards.

1. Improper electrical installation

2. Damage electrical appliance and equipment

3. Lighting fitting overheating

The electricity users are not aware of the followings as electrical Hazards

1. Ungrounded circuit and equipment.

2. Coiled extension leads.

3. Covered ventilation holes in electrical equipment.

The safety measures awareness among electricity users.

1. Proper electrical insulation

2. Switch off and unplug equipment to be repaired.

3. Use nonconductive material to remove a victim from the conductor.

The safety measures not awareness among electricity users.

1. Uncoiled extension cord on the drum

2. Uncovered slots of electrical machine and equipment.

3. When circuit breaks or fuses trip don't reset

\section{Discussion of the Findings}

Ensuring safety and raising awareness among individual is very important as knowledge is wealth. Electrical hazard posed a significant risk of death and injuries to individual therefore, attention to safety is the necessary as first step in any environmental set up. The findings from Table 1 agreed with the work of Kolak (2007) which said electric shock occurs if the body contacts with electric circuit. This may cause serious burns, muscle damage and may kill victim by stopping the heart or breathing. In support of this Smith (2006) opined that when the body is in contact with live wire or any live components of an energized electrical device and also in contact with grounded object will receive a shock. The risk of receiving electrical shock is greater if one stand in a wet floor or touch live wire with wet body. If someone comes in contact with live electrical source, do not touch the victim with your bear hand. The person must be free either by switching off supply or with the use of insulating materials such as dry wood, clothing, rubber and when people are ignorant of hazards of using electricity they often becomes a victim of electrical shock or electrocution and related hazards (MacKinnon, 2010)

The major causes of fire in buildings are arcing or sparking due to lose electrical connections, it was confirmed (MacKinnon, 2010) which assures that the causes of electric fire in a building is overheating of electrical equipment, materials and appliances such as socket, lamp holder and others, wrong use of cable size during installation, overloading of socket, wrong use of fuse and lose electrical connection. OSHA, (2009) recommends way to avoid the fire due to electricity in a building. He said that, the electricity user must avoid overloading of socket, ventilation hole in electrical equipment, appliances and machines must not be locked, using of extension cord that are of correct size or rating for the equipment use. The knowledge of safety measures need to be passed to electricity users as knowledge is the seed of tomorrow's change.

\section{Conclusion}

The study revealed the level of awareness of electrical hazards and safety measures knowledge among electricity users in Minna metropolis. From the study it has become cleared that many users of electricity are not well inform or aware about electricity hazards and safety measures. No wonder the implications of these is been seen in numbers of electricity accidents witness in homes and work places. To avoid all forms electricity 
accident witness in Minna metropolis all hands must be on deck to see that electricity users have adequate awareness of electricity hazards and safety.

The following recommendations were made:

\section{Recommendations}

1. Electricity users should be well sensitized by Government, NGOs, electrical power providers and Manufacturer of electrical products on the hazards pose well using electricity through Televisions Radio, posters, public lectures and other means of communication.

2. The electricity users should be well informed on the safety measures which will help in protecting lives and property of the users of electricity through safety posters, public lectures and other means.

3. Hazards and safety practices attributed to each equipment, appliances and machines should be conspicuously printed on it. This will remind the users when using the appliances, equipment and machines.

\section{References}

[1]. Bakshi, U.A., and Bakshi, V. U. (2009). Basic electrical engineering. Pune, India. Technical publications.

[2]. Cardick, J., Capelli-Schellpfeffer, T. and Neitzel, D.K., (2006). Electrical safety handbook. New York MC Graw-Hill Companies, Inc.

[3]. Floyd, L., Rogers, M., and UzoKa, U (2008). Home electricity safety retrieved on July, 152013 from http:/www.safeelectricity.org/new/news.room

[4]. Janick, C. A. (2008). Occupational Fatalities due to Electrocutions in the Construction Industry. Journal of Safety Research, 39: $617-621$.

[5]. Kolak, J. (2007). Electrical Safety: Elements of an effective program. Professional Safety. 52(2):18-24.

[6]. MacKinnon, J.T (2010). Important electrical and fire safety tips for families. Publication of Plymouth Utilities

[7]. Networks (n.d). The safe use of electricity in the home. Retrieved on May, 132013 from http:/www.esb.ie/esbnetworks

[8]. OSHA, (2009). Occupational Safety and Health Association fact file 2002-2009, retrieved on August, 102013 from www.cdcgov/osha.com.

[9]. Selp, G.G. (2000). Electrical installation handbook. Werbeagentur, John Wiley and Sons Chichester Publisher

[10]. Smith, A.M., (2006). Assessment of the injured athlete. In J. Crossman (ed) Coping with sports injuries: Psychological strategies for rehabilitation. New York: Oxford University Press.

[11]. Taylor G., Easter, K., and Hegney, R. (2004). Enhancing occupational safety and health. London, Elservier Butterworth Henemann Ltd. 